\title{
HC-Induced Deactivation in CO Conversion at Diesel Oxidation Catalysts
}

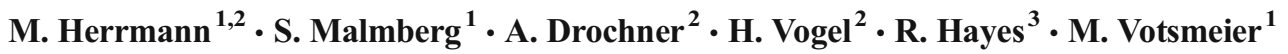

Received: 22 September 2015 / Revised: 28 June 2016 / Accepted: 11 July 2016 / Published online: 8 August 2016

(C) Springer International Publishing Switzerland 2016

\begin{abstract}
This paper examines the activity of a platinum catalyst for the oxidation of $\mathrm{CO}$ under conditions of temperature cycling. Each cycle consists of an ignition and extinction curve obtained with a linear temperature ramp. It is shown that the catalyst activity is higher for the first ignition cycle than for the subsequent ones regarding $\mathrm{CO}$ conversion. The activity for the extinction portion of each cycle is the same for all cycles. It is proposed that the loss of catalyst activity results from the deposition of hydrocarbon residues during the extinction part of the cycle. The catalyst activity can be completely restored by heating the catalyst to $350{ }^{\circ} \mathrm{C}$ in the presence of oxygen and nitrogen.
\end{abstract}

Keywords Diesel oxidation catalyst · Deactivation . Reactivation $\cdot \mathrm{HC}$ intermediates $\cdot$ Inverse hysteresis

\section{Introduction}

To date, most simulation work on exhaust treatment systems is based on the Langmuir-Hinshelwood-Hougen-Watson (LHHW) approach, i.e., it is assumed that the rates of the surface reactions are controlled by competition for surface sites and that steady state surface concentrations are instantly

M. Votsmeier

martin.votsmeier@eu.umicore.com

Umicore AG \& Co. KG, D-63403 Hanau-Wolfgang, Germany

2 Ernst-Berl-Institut, Technische Universität Darmstadt, D-64287 Darmstadt, Germany

3 Department of Chemical and Materials Engineering, University of Alberta, Edmonton, AB T6G 2V4, Canada established for given gas phase conditions [1]. One important consequence arising from these assumptions is that global rate laws can be formulated, which describe the observed rates $r$ as a function of only the current gas phase concentrations and the surface temperature $r\left(\mathrm{c}_{\mathrm{gas}}, \mathrm{T}\right)$, and not the history of operating conditions.

It has been pointed out [2-10] that under typical exhaust treatment operating conditions, reversible activation/ deactivation effects can be observed. This is a fundamental challenge for the currently established LHHW-based modeling approach since, in the presence of the activation/ deactivation effects, the observed reaction rate becomes a function of the recent catalyst history.

One prominent example for such a reversible activation/ deactivation effect is the inverse hysteresis during NO oxidation observed by Hauptmann et al. [2]. The effect can be explained by a reversible oxidation of the platinum surface by $\mathrm{NO}_{2}$ or $\mathrm{O}_{2}$ at higher temperatures and a reduction of the platinum oxides by $\mathrm{NO}$ at lower temperatures. The inverse hysteresis effect has been investigated in more detail in a number of studies [4-7], and it has been shown that for simple gas mixtures, the hysteresis behavior can be quantitatively reproduced by global [5-7] as well as microkinetic models [2]. Apart from the inverse NO hysteresis on platinum, further deactivation and reactivation effects caused by different precious metal oxidation states were reported for $\mathrm{NO}, \mathrm{CO}$, and propene conversion on platinum as well as on palladium by Dubbe et al. [7]. They assessed the reducing potential of single pollutants and pollutant's gas mixtures, proposed a modeling approach, and simulated the effects in the case for $\mathrm{NO}$ for both noble metals.

The practical relevance of such reversible activation/ deactivation effects for the adjustment of an optimal $\mathrm{NO} /$ $\mathrm{NO}_{2}$ ratio has been highlighted by Bandl-Konrad et al. [10] and Arvajová et al. [11]. They showed that a reducing CO and 
$\mathrm{C}_{3} \mathrm{H}_{6}$ pulse can restore the activity of deactivated $\mathrm{PtO}_{\mathrm{X}}$ while keeping lean conditions.

A similar inverse hysteresis effect has recently been reported by Abedi at al [3] for the oxidation of hydrocarbon/CO mixtures. It was observed that during a heat-up/cool-down sequence, the $\mathrm{CO} / \mathrm{HC}$ ignition occurred at lower temperature than the corresponding extinction. Using DRIFTspectroscopy on $\mathrm{Pt} / \mathrm{Al}_{2} \mathrm{O}_{3}$ powder samples, the effect was attributed to the formation of $\mathrm{HC}$ intermediates competing with $\mathrm{CO}$ for active sites.

In this work, we further investigate the activation/ deactivation effect reported by Abedi et al. [3]. By following the $\mathrm{CO}$ conversion during several consecutive light-off experiments, the origins of this effect are examined. We also study the reversibility of the deactivation process. Furthermore, we systematically investigate the impact of the pretreatment on the catalyst's activity.

\section{Materials and Methods}

\subsection{Apparatus}

The apparatus used in this work consisted of a gas mixing unit, a gas preheater with a reactor and an analyzer module. Mass flow controllers were used to control and monitor the flow rate of each gas species. For experiments with water, steam was dosed to the feed using an evaporator system. Before passing through the monolith, the gas mixture was heated in a tubular furnace. To ensure a uniform temperature profile and to enhance mixing of the gases, static mixers were installed in the oven.

\subsection{Catalyst and Reactor}

A monolithic diesel oxidation model catalyst (Umicore AG \& Co. $\mathrm{KG}, \mathrm{Pt} / \mathrm{Al}_{2} \mathrm{O}_{3}$, length $7.62 \mathrm{~cm}$, diameter $2.54 \mathrm{~cm}, 400$ cpsi, 4.33 mil wall thickness, hydrothermally aged $\left(600{ }^{\circ} \mathrm{C}\right.$ for $10 \mathrm{~h}$ ), noble metal loading $80 \mathrm{~g} / \mathrm{ft}^{3}$ ) was used for all experiments. The monolith was wrapped with insulation and placed in a stainless steel tubular reactor taking care to ensure no gas bypass of the monolith occurred.

\subsection{Temperature}

Temperature profiles were monitored using four K-type thermocouples. One was placed $0.5 \mathrm{~mm}$ in front of the catalyst, two in central channels ( 0.5 and $55 \mathrm{~mm}$ behind the inlet), and one $10 \mathrm{~mm}$ behind the outlet. For reason that the two thermocouples inside the catalyst block fewer than $1 \%$ of the channels, the impact on the flow field is assumed to be negligible. For reference purposes, the temperature measured $0.5 \mathrm{~mm}$ in front of the catalyst's entrance is used.

\subsection{Analyzer}

$\mathrm{NO}$ and $\mathrm{NO}_{\mathrm{X}}$ at the reactor outlet were analyzed using a chemiluminescence detector (CLD). Whereas a flame ionization detector (FID) was applied for the hydrocarbons assay. For the CO monitoring, an IRD measurement was utilized, which is based on heat generation by infrared radiation passing a cuvette filled with the sample.

\subsection{Pretreatment}

Before each experiment was performed, the catalyst was treated with a defined mixture of inert gas species (see Table 1) while a temperature ramp from 80 to $350^{\circ} \mathrm{C}$ and back to $80^{\circ} \mathrm{C}$ with a heating rate of $8 \mathrm{~K} / \mathrm{min}$ was employed.

\subsection{Light-Off/Light-Down Experiments}

After the pretreatment, several light-off/light-down experiments were performed. The ramp reached from 80 to $350{ }^{\circ} \mathrm{C}$ and back to $80{ }^{\circ} \mathrm{C}$ with a heating rate of $8 \mathrm{~K} / \mathrm{min}$. The preheated gas stream with the inert gas species $\left(6 \% \mathrm{O}_{2}\right.$, $11 \% \mathrm{CO}_{2}$, and $8 \% \mathrm{H}_{2} \mathrm{O}, \mathrm{N}_{2}$ balance gas) was mixed with

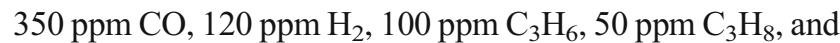
$270 \mathrm{ppm} \mathrm{NO}$ at a space velocity of $25,000 \mathrm{~h}^{-1}$ before reaching the catalyst.

\section{Results and Discussion}

\subsection{Hysteresis at the Pt-Catalyst}

Two consecutive ignition/extinction experiments were performed using the temperature ramp scheme shown in Fig. 1a. The three ramps represent the conditioning ramp and the subsequent two ignition/extinction experiments. The conversion of the pollutant $\mathrm{CO}$, total hydrocarbons, and $\mathrm{NO}$ during these experiments is shown in Fig. 1b-c.

Figure $1 \mathrm{~b}$ shows the $\mathrm{CO}$ ignition and extinction curves. The second light-off curve describing the conversion of $\mathrm{CO}$ to $\mathrm{CO}_{2}$ is shifted to a higher temperature of approximately $20 \mathrm{~K}$ compared to the first one. The light-down curves are, however, congruent for both experiments and lay between the

Table 1 Gas species for the different pretreatments of the catalyst

\begin{tabular}{lllll}
\hline Pretreatment & $\mathrm{N}_{2}$ & $\mathrm{CO}_{2} / \%$ & $\mathrm{O}_{2} / \%$ & $\mathrm{H}_{2} \mathrm{O} / \%$ \\
\hline $\mathrm{N}_{2} / \mathrm{CO}_{2}$ & Balance gas & 11 & - & - \\
$\mathrm{N}_{2} / \mathrm{CO}_{2} / \mathrm{O}_{2}$ & Balance gas & 11 & 6 & - \\
$\mathrm{N}_{2} / \mathrm{CO}_{2} / \mathrm{H}_{2} \mathrm{O}$ & Balance gas & 11 & - & 8 \\
$\mathrm{~N}_{2} / \mathrm{CO}_{2} / \mathrm{H}_{2} \mathrm{O} / \mathrm{O}_{2}$ & Balance gas & 11 & 6 & 8 \\
\hline
\end{tabular}


Fig. 1 a Schematic temperature ramp for a conditioning phase in $\mathrm{N}_{2}, \mathrm{CO}_{2}$, and $\mathrm{O}_{2}$ and subsequent two ignition/extinction experiments for $350 \mathrm{ppm} \mathrm{CO}$, $270 \mathrm{ppm}$ NO, $100 \mathrm{ppm}$ propene, $120 \mathrm{ppm} \mathrm{H}_{2}, 50 \mathrm{ppm} \mathrm{C}_{3} \mathrm{H}_{8}, 6 \%$ $\mathrm{O}_{2}, 11 \% \mathrm{CO}_{2}, 8 \% \mathrm{H}_{2} \mathrm{O}$ and $\mathrm{N}_{2}$ balance gas at a space velocity of $25,000 \mathrm{~h}^{-1}$. The conversion of $\mathrm{CO}, \mathrm{NO}$, and $\mathrm{HC}$ during the experiments is depicted in $\mathbf{b}-\mathbf{d}$. The solid lines represent the ignition branches and the dashed lines the extinction

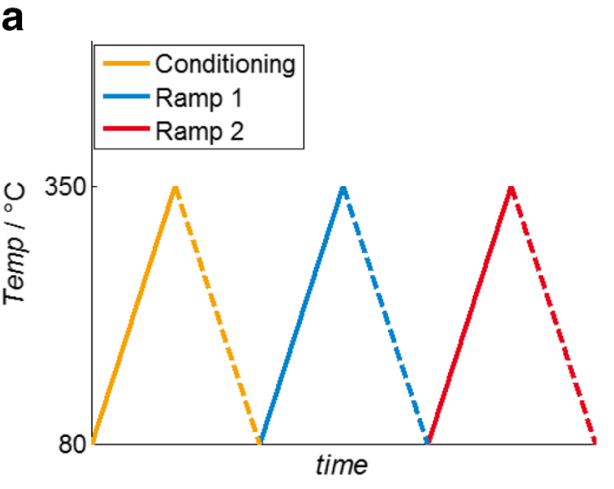

b

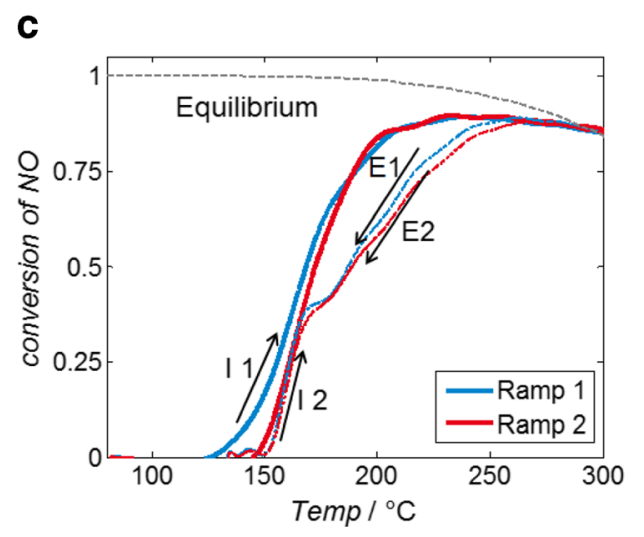

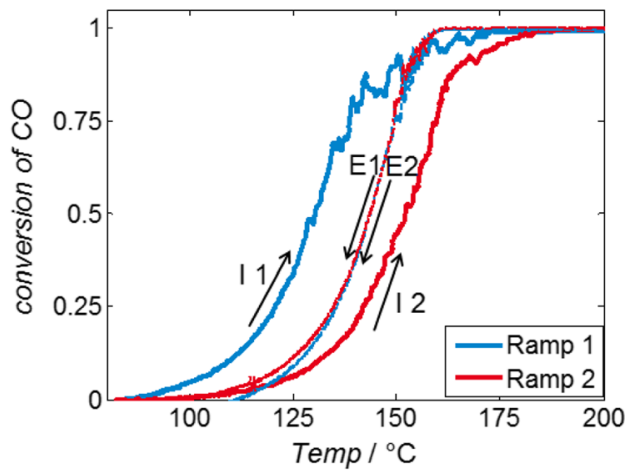

d

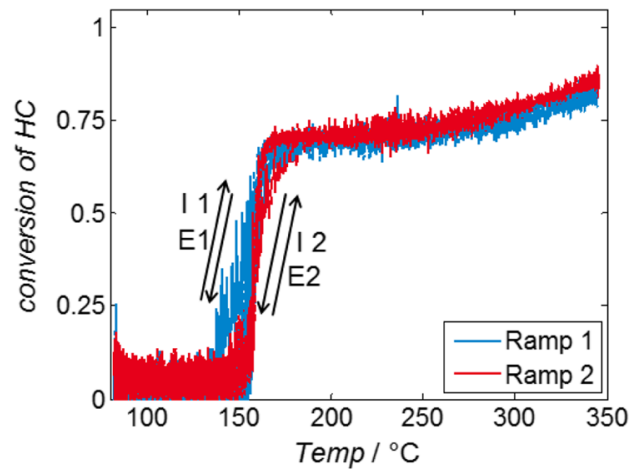

first and the second light-off. Obviously, a deactivation takes place after or during the first light-off which leads to an inverse hysteresis for the first ramp and normal hysteresis for the second ramp.

In contrast to the conversion of $\mathrm{CO}$ to $\mathrm{CO}_{2}$, the two lightoff curves of the $\mathrm{NO}$ oxidation do not show significant differences (Fig. 1c). However, NO conversion consequently shows a poorer performance during the extinction than during the ignition, which is a strong evidence for a reversible deactivation that takes place at high temperatures and is reversed at low temperatures. Around $300{ }^{\circ} \mathrm{C}$, the CLD detecting NO shows a slightly higher conversion than the expected one according to the thermodynamical equilibrium. This deviation can be explained by inaccuracies in the assay.

For the total hydrocarbon oxidation (Fig. 1d), both ignition and extinction branches show substantial oscillations. However, the ignition and extinction temperature can be determined and strong hysteresis phenomena can be excluded. Indeed, the propene is completely oxidized by $350{ }^{\circ} \mathrm{C}$, whereas very little propane is converted up to $350{ }^{\circ} \mathrm{C}$.

Although deactivation phenomena can be observed in NO and $\mathrm{CO}$ conversion during the consecutive ignition/extinction experiments, their impacts on the pollutant conversions are different. While an inverse hysteresis is constantly observed in the case of $\mathrm{NO}$ during the heating/cooling cycles, the $\mathrm{CO}$ conversion features a switch from an inverse hysteresis during the first cycle to a normal hysteresis during the second cycle.
The phenomenon of a constant inverse hysteresis in NO conversion can be explained by $\mathrm{Pt}$ oxide formation with formed $\mathrm{NO}_{2}$ and/or $\mathrm{O}_{2}$ at high temperatures and a reduction of the active species by $\mathrm{NO}, \mathrm{CO}$, or $\mathrm{HC}$ species at low temperatures $[2,5,7]$.

However, the effect of a switch from a normal hysteresis to an inverse hysteresis in $\mathrm{CO}$ conversion during consecutive light-off/light-down experiments has not been reported so far and will be investigated in detail in the following sections.

\subsection{Deactivation in CO Oxidation}

Three consecutive ignition/extinction experiments were then performed using the temperature ramp scheme shown in Fig. 2a. The four ramps represent the conditioning ramp and the subsequent three ignition/extinction experiments.

Figure $2 \mathrm{~b}$ shows the ignition curves of these experiments. The conversion of $\mathrm{CO}$ to $\mathrm{CO}_{2}$ shifts to a temperature approximately $20 \mathrm{~K}$ higher after the first ignition. A deactivation takes place. The ignition and extinction temperature remain constant for the deactivated catalyst during all following lightoff/light-down cycles. The deactivation is irreversible under the applied conditions.

It seems to be illogical that such an effect is caused only by noble metal oxidation because under these circumstances, the catalyst should not be in the most active state after a conditioning phase in an oxidative environment. A reduction of 
a

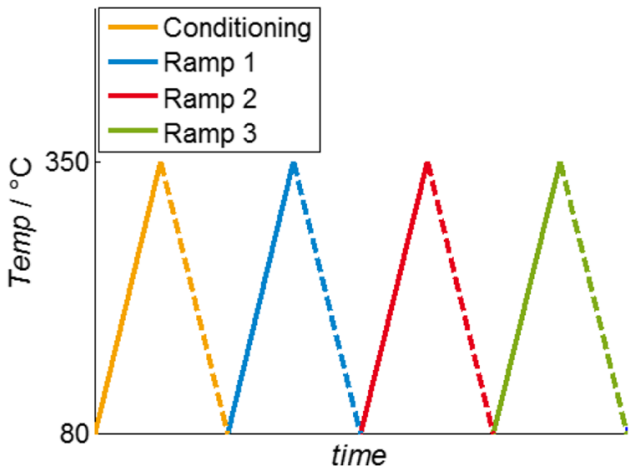

b

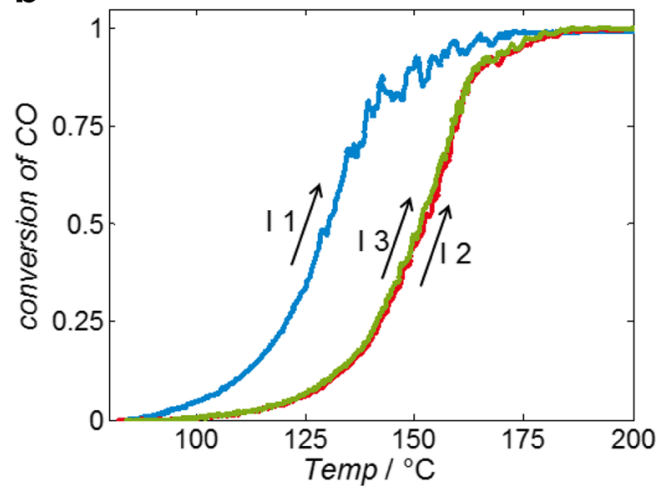

Fig. 2 a Schematic temperature ramp for a conditioning phase in $\mathrm{N}_{2}$, $\mathrm{CO}_{2}$, and $\mathrm{O}_{2}$ and subsequent three ignition/extinction experiments for $350 \mathrm{ppm} \mathrm{CO}$ in $270 \mathrm{ppm} \mathrm{NO}, 100 \mathrm{ppm}$ propene, $120 \mathrm{ppm} \mathrm{H}_{2}, 50 \mathrm{ppm}$ $\mathrm{C}_{3} \mathrm{H}_{8}, 6 \% \mathrm{O}_{2}, 11 \% \mathrm{CO}_{2}, 8 \% \mathrm{H}_{2} \mathrm{O}$ and $\mathrm{N}_{2}$ balance gas at a space velocity of $25,000 \mathrm{~h}^{-1}$. The conversion of $\mathrm{CO}$ during the first, second, and third ignition is depicted in $\mathbf{b}$

noble metal, which can be caused by NO or other reducing species at low temperatures would probably result in an activated catalyst at the beginning of each light-off experiment. We do not claim that noble metal oxidation does not influence the $\mathrm{CO}$ ignition curve, which has already been reported by Hauptmann et al. and by Dubbe et al. [5, 7]. However, we do claim that it is unlikely that the reported effect in this work is only caused by the formation of $\mathrm{PtO}_{\mathrm{X}}$.

Another deactivation phenomenon is the formation of $\mathrm{HC}$ intermediates, which can occur during the $\mathrm{C}_{3} \mathrm{H}_{6}$ ignition. In this context, Abedi et al. have investigated the oxidation of $\mathrm{CO} /$ $\mathrm{C}_{3} \mathrm{H}_{6}$ mixtures at $\mathrm{Pt} / \mathrm{Al}_{2} \mathrm{O}_{3}$ and reported a switch form a normal to an inverse hysteresis for both pollutants with decreasing $\mathrm{CO} /$ $\mathrm{C}_{3} \mathrm{H}_{6}$ ratio [3]. They not only observed this effect but also detected the HC intermediates applying DRIFT-spectroscopy.

\subsection{What Is the Reason for the Deactivation?}

To verify if the deactivation in CO conversion is caused by the formation of $\mathrm{HC}$ intermediates or rather by other deactivation mechanisms, two consecutive ignition/extinction experiments were performed in the absence of hydrocarbons after a conditioning phase according to the ramping protocol shown in
Fig. 3a. Unlike the previous experiments, the conditioning gas contained hydrocarbons and was equal to the deactivating gas mixture used for the ignition/extinction experiments in Figs. 1 and 2. The CO conversion during the first and the second ignition branch is depicted in Fig. 3b.

The CO ignition curve, which was obtained directly after the conditioning phase in the gas mixture containing hydrocarbons, is shifted to a higher temperature of approximately $20 \mathrm{~K}$ at $50 \%$ conversion compared to the second ignition curve. Thus, a reversed trend can be observed for this experiment compared to the two previous ones. At this state, it seems logical to assume that the deactivation is somehow caused by hydrocarbons because the conditioning in their presence deactivated the catalyst. Further, the experiment's results provide strong evidence that the deactivation is not permanent because the catalyst reaches a more active state after a light-off/light-down cycle in the absence of hydrocarbons. Obviously, a reactivation takes place which will be investigated in detail in the following sections.

\subsection{Reactivation of the Catalyst}

If a temperature ramp up to $350^{\circ} \mathrm{C}$ is applied in the absence of pollutants, the deactivation can completely be reversed. To examine the reactivation of the catalyst, a sequence of lightoff/light-down experiments was performed using the ramping protocol shown in Fig. 4a. The catalyst was conditioned in $\mathrm{N}_{2} /$ $\mathrm{O}_{2} / \mathrm{CO}_{2}$, and three ignition/extinction experiments were performed. Following this, the catalyst was again conditioned and three more ignition/extinction experiments were conducted. Figure $4 \mathrm{~b}$ shows the first, second, and third ignition curve obtained after the conditioning. The corresponding temperatures for $50 \%$ CO conversion are presented in Fig. 5.

An activated light-off can be observed after the first and the second conditioning phase which shows $50 \%$ conversion at $130{ }^{\circ} \mathrm{C}$. The following extinctions occur at approximately $13 \mathrm{~K}$ higher temperature (see Fig. 5). The subsequent lightoffs require approximately $150{ }^{\circ} \mathrm{C}$ for $50 \% \mathrm{CO}$ conversion, whereas the extinction curves had $50 \%$ conversion at $143^{\circ} \mathrm{C}$, the same as the first extinction. If we attribute the effect to the formed $\mathrm{HC}$ intermediates investigated by Abdei et al. [3], it seems to be logical that the intermediates are formed after the first ignition (during the first propene light-off). They lead to a deactivation of the platinum which remains constant for following light-offs and light-downs. The differences in ignition and extinction temperature at the deactivated catalyst can be explained by effects such as thermal inertia or multiple steady states [2]. An applied temperature ramp up to $350{ }^{\circ} \mathrm{C}$ in the absence of pollutants is sufficient to remove all of the intermediates resulting in a re-activation of the platinum.

We can speculate on when during the cycle of ignition and extinction the hydrocarbon intermediates are formed. It is reasonable to assume that the intermediates are formed and 
Fig. 3 b Conversion of $350 \mathrm{ppm}$ $\mathrm{CO}$ during two consecutive ignition/extinction experiments in 270 ppm NO, $120 \mathrm{ppm} \mathrm{H}_{2}, 6 \%$ $\mathrm{O}_{2}, 11 \% \mathrm{CO}_{2}, 8 \% \mathrm{H}_{2} \mathrm{O}$ and $\mathrm{N}_{2}$ balance gas at a space velocity of $25,000 \mathrm{~h}^{-1}$ after a conditioning phase in the same gas mixture with the addition of $100 \mathrm{ppm}$ $\mathrm{C}_{3} \mathrm{H}_{6}$ and $50 \mathrm{ppm}_{3} \mathrm{H}_{8}$. A schematic temperature ramp for the procedure can be seen in a

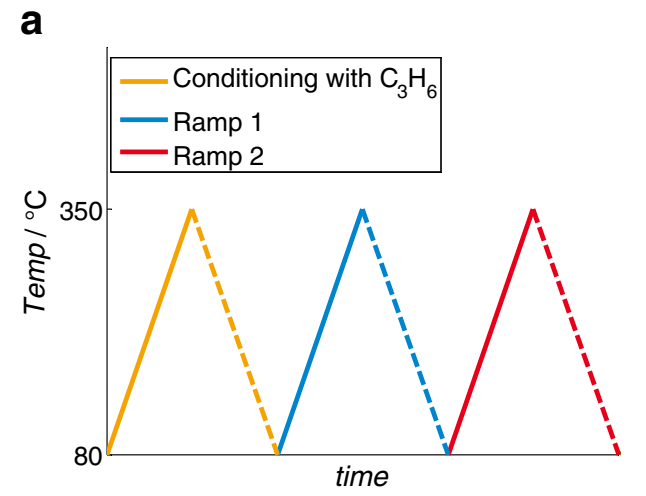

b

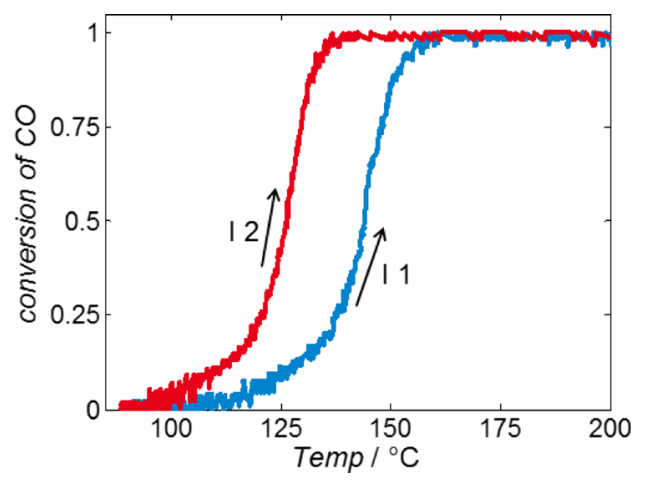

remain stable on the surface more readily at lower temperatures. Thus, they would be formed at the earlier stages of the ignition curve and would affect the ignition of all experiments equally. It is also likely that the intermediates are formed from propene and not from propane owing to the fact that propane shows nearly no conversion under the applied conditions. For a fresh catalyst with a clean surface, hydrocarbon intermediates probably do not form until the oxidation of $\mathrm{CO}$ is

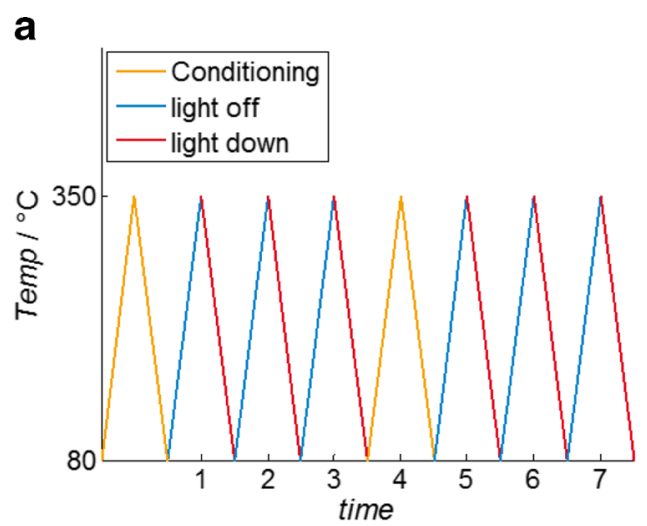

b

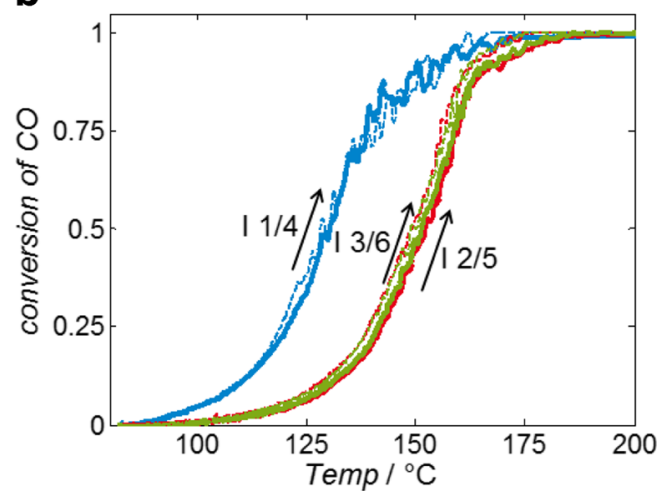

Fig. 4 a Schematic temperature ramping sequence for a conditioning phase and subsequent three ignition/extinction experiments, conducted twice. The conditioning ramp was performed in $\mathrm{N}_{2}, \mathrm{CO}_{2}$, and $\mathrm{O}_{2}$, and the ignition/extinction experiments were conducted in $350 \mathrm{ppm} \mathrm{CO}$, $270 \mathrm{ppm} \mathrm{NO}, 100 \mathrm{ppm}$ Propene, $120 \mathrm{ppm} \mathrm{H}_{2}, 50 \mathrm{ppm}_{3} \mathrm{H}_{8}, 6 \% \mathrm{O}_{2}$, $11 \% \mathrm{CO}_{2}, 8 \% \mathrm{H}_{2} \mathrm{O}$ and $\mathrm{N}_{2}$ balance gas at a space velocity of $25,000 \mathrm{~h}^{-1}$. The conversion of $\mathrm{CO}$ during the first, second, third/fourth, fifth, and sixth ignition is depicted in $\mathbf{b}$ complete, since the surface of the fresh catalyst is mostly covered by adsorbed CO [12]. After $100 \%$ conversion is reached, at higher temperature, it is less likely that there would be $\mathrm{HC}$ residues left on the surface. At temperatures well above the light-off, all the $\mathrm{C}_{3} \mathrm{H}_{6}$ will be converted within the first millimeters of the channel, so that most of the catalyst is subjected to an $\mathrm{HC}$-free gas mixture that is very similar to the gas mixture applied during catalyst regeneration. It can therefore be assumed that at high temperatures, most of the catalyst is free of $\mathrm{HC}$ residues. It has been observed that the light-off initially occurs at the catalyst exit, and the reaction front progresses to the entrance [13]. For the extinction front, a reverse behavior is expected, that is, the extinction front moves in the flow direction from the reactor entrance to the exit. We therefore suggest that the $\mathrm{HC}$ residues are deposited during the extinction phase of the cycle and are laid down progressively as the extinction progresses. These residues would thus be present and inhibit the $\mathrm{CO}$ oxidation during the next ignition cycle. If the $\mathrm{HC}$ intermediates are all removed by the end of the ignition phase, then the next extinction portion would lay down new intermediates in an equivalent manner to the first ignition phase, and thus there would be no accumulation of the intermediates on the surface. Thus, all subsequent ignition cycles would be the same, which is consistent with the observed behavior.

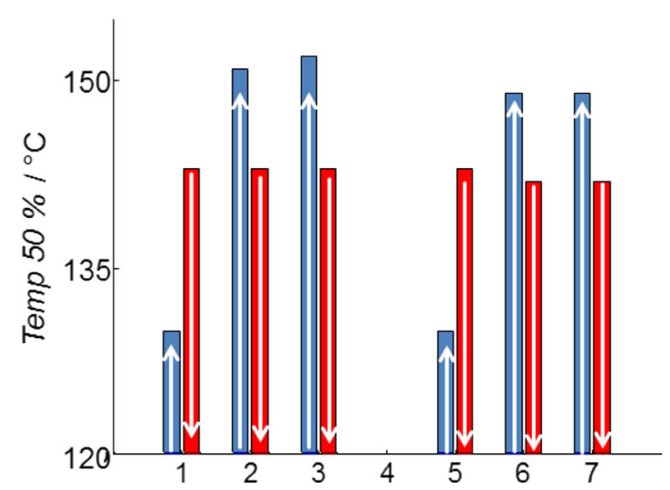

Fig. 5 Required temperature for $50 \% \mathrm{CO}$ conversion in the presence of $\mathrm{C}_{3} \mathrm{H}_{6}$ during ignition (blue) and extinction (red) for the first, second, and third ramp after a pretreatment in $\mathrm{N}_{2}, \mathrm{CO}_{2}$, and $\mathrm{O}_{2}$ 
Table 2 Required temperature for $50 \% \mathrm{CO}$ conversion in the presence of $\mathrm{C}_{3} \mathrm{H}_{6}$ for the first, second, and third light-off (LO), with different pretreatments of the catalyst preceding the first LO

\begin{tabular}{llll}
\hline Pretreatment & $\begin{array}{l}T_{50 \%} \text { first } \\
\mathrm{LO} / \mathrm{C}^{\circ}\end{array}$ & $\begin{array}{l}T_{50 \%} \text { second } \\
\mathrm{LO} / \mathrm{C}^{\circ}\end{array}$ & $\begin{array}{l}T_{50 \%} \text { third } \\
\mathrm{LO} / \mathrm{C}^{\circ}\end{array}$ \\
\hline $\mathrm{N}_{2} / \mathrm{CO}_{2}$ & 137 & 149 & 149 \\
$\mathrm{~N}_{2} / \mathrm{CO}_{2} / \mathrm{O}_{2}$ & 130 & 151 & 152 \\
$\mathrm{~N}_{2} / \mathrm{CO}_{2} / \mathrm{H}_{2} \mathrm{O}$ & 131 & 147 & 148 \\
$\mathrm{~N}_{2} / \mathrm{CO}_{2} / \mathrm{H}_{2} \mathrm{O} / \mathrm{O}_{2}$ & 125 & 148 & 148 \\
\hline
\end{tabular}

\subsection{Influence of the Pretreatment}

The required temperatures for $50 \% \mathrm{CO}$ conversion of the first, second, and third ignition after different pretreatments are shown in Table 2. Before each pretreatment was carried out, the catalyst was in a deactivated state. A depiction of the results in Table 2 is provided in Fig. 6. The results show that the catalyst's pretreatment strongly affects its activity. The addition of water or oxygen as a single component to $\mathrm{N}_{2}$ / $\mathrm{CO}_{2}$ during the pretreatment lowers the first ignition temperature by approximately $7 \mathrm{~K}$ compared to the original pretreatment. The addition of both species water and $\mathrm{O}_{2}$ even results in $12 \mathrm{~K}$ ignition point depression. The deactivated catalyst always shows an ignition temperature $\left(T_{50 \%}\right)$ of approximately $150^{\circ} \mathrm{C}$.

The fact that a pretreatment in the absence of $\mathrm{H}_{2} \mathrm{O}$ and $\mathrm{O}_{2}$ leads to an incomplete re-activation might be a hint that different mechanisms are responsible for the removal of $\mathrm{HC}$ intermediates. While probably only desorption processes occur in a gas mixture of $\mathrm{N}_{2}$ and $\mathrm{CO}_{2}$, the addition of oxygen obviously results in an $\mathrm{HC}$-intermediate oxidation, whereas $\mathrm{H}_{2} \mathrm{O}$ could be a reactant for a steam reforming reaction. The idea of different reactivation mechanisms is underpinned by the fact that the combination of $\mathrm{H}_{2} \mathrm{O}$ and $\mathrm{O}_{2}$ as reactivating gas mixture leads to a higher degree of reactivation compared to the single components. Thus, one could speculate that there might be three different types of $\mathrm{HC}$ intermediates, which can be removed from the catalyst surface either by desorption, oxidation, or the steam reforming reaction.

\section{Conclusions}

The $\mathrm{CO}$ conversion during the oxidation of $\mathrm{CO} / \mathrm{HC}$ mixtures with oxygen on platinum was studied in consecutive heat-up/ cool-down cycles. It was shown that during the first heat-up cycle on a clean catalyst surface, a lower light-off temperature is observed than during the following cycles. The effect can be explained by a reversible blocking of active sites by $\mathrm{HC}$ residues. This deactivation can be reversed by a heat-up/cooldown cycle with an oxidizing exhaust mixture not containing any HC. A complete reactivation is obtained with mixtures that contain $\mathrm{O}_{2}$ and/or $\mathrm{H}_{2} \mathrm{O}$, while a mixture of $\mathrm{CO}_{2}$ and $\mathrm{N}_{2}$ yields only a partial regeneration.

The effect presented in this paper is a further example of a reversible activation/deactivation effect that occurs under typical exhaust aftertreatment operating conditions. Such activation/deactivation effects pose a significant challenge for simulation of exhaust aftertreatment devices, since current simulation approaches are mostly based on the assumption of steady state surface conditions, i.e., it is assumed that the
Fig. 6 Required temperature for $50 \%$ CO conversion in the presence of $\mathrm{C}_{3} \mathrm{H}_{6}$ for the first, second, and third light-off after a pretreatment in a $\mathrm{N}_{2} / \mathrm{CO}_{2}, \mathbf{b ~ N} \mathrm{N}_{2} /$ $\mathrm{CO}_{2} / \mathrm{O}_{2}, \mathbf{c ~} \mathrm{N}_{2} / \mathrm{CO}_{2} / \mathrm{H}_{2} \mathrm{O}$, and $\mathbf{d}$ $\mathrm{N}_{2} / \mathrm{CO}_{2} / \mathrm{H}_{2} \mathrm{O} / \mathrm{O}_{2}$ a

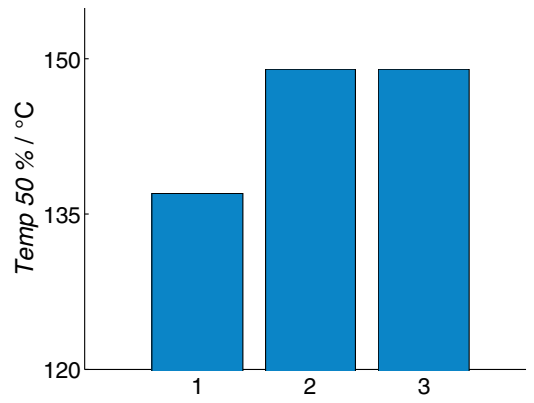

C

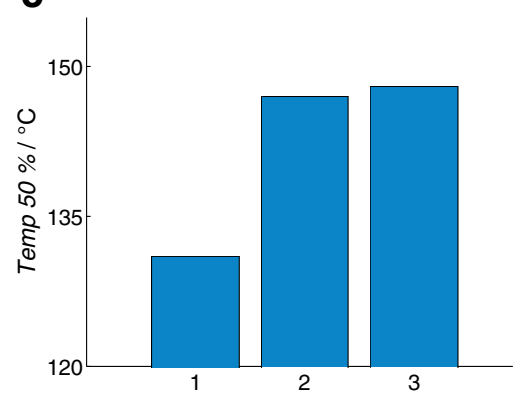

b

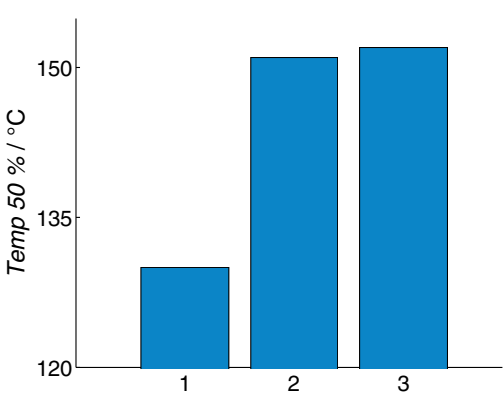

d

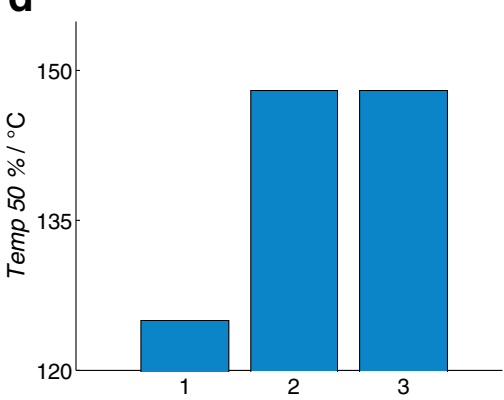


kinetics can be described by a rate law as a function of only the current gas concentrations and surface temperatures with no influence of the recent catalyst operation history.

Ultimately, the goal is to obtain a mechanistic understanding of the different activation/deactivation effects and to include a physical description of the effects in the simulation models. However, given the number and complexity of the effects, the derivation of a quantitative model description of them is a major challenge.

A sound understanding of the different activation/ deactivation behavior is also needed if the effects are not explicitly simulated, since, in this case, the models will implicitly represent a certain activation state that is determined by the test sequence applied for model calibration. Therefore, it is important that the test protocols represent realistic operating conditions also with respect to the activation/deactivation effects. Concerning the deactivation effect discussed in this paper, this means that if light-off tests are applied for model calibration, a realistic preconditioning needs to be ensured before each light-off test to ensure that the desired initial catalyst surface condition is achieved.

\section{References}

1. Güthenke, A., Chatterjee, D., Weibel, M., Krutzsch, B., Kocı, P., Marek, M., Nova, I., Tronconi, E.: Current status of modelling lean exhaust gas aftertreatment catalysis. Adv Chem Eng 33, 103-211 (2007)

2. Hauptmann, W., Votsmeier, M., Gieshoff, J., Drochner, A., Vogel, $\mathrm{H}$.: Inverse hysteresis during the NO oxidation on Pt under lean conditions. Appl Catal B Environ 93, 22-29 (2009)
3. Abedi, A., Hayes, R., Votsmeier, M., Epling, W.: Inverse hysteresis phenomena during $\mathrm{CO}$ and $\mathrm{C}_{3} \mathrm{H}_{6}$ oxidation over a $\mathrm{Pt} / \mathrm{Al}_{2} \mathrm{O}_{3}$ catalyst. Catal Lett 142, 930-935 (2012)

4. Hauff, K., Tuttlies, U., Eigenberger, G., Nieken, U.: Platinum oxide formation and reduction during $\mathrm{NO}$ oxidation on a diesel oxidation catalyst-experimental results. Appl Catal B Environ 123-124, 107-116 (2012)

5. Hauff, K., Dubbe, H., Tuttlies, U., Eigenberger, G., Nieken, U.: Platinum oxide formation and reduction during $\mathrm{NO}$ oxidation on a diesel oxidation catalyst - macrokinetic simulation. Appl Catal B Environ 129, 273-281 (2013)

6. Hauff, K., Boll, W., Tischer, S., Chan, D., Tuttlies, U., Eigenberger, G., Deutschmann, O., Nieken, U.: Macro- and microkinetic simulation of diesel oxidation catalyst: effect of aging, noble metal loading and platinum oxidation. Chem Ing Tech 85, 673-685 (2013)

7. Dubbe H., Eigenberger G., Nieken U., Hysteresis phenomena on platinum and palladium based diesel oxidation catalysts (DOCs), Emissions Control Science \& Technology: accepted manuscript (2016)

8. Després, J., Elsener, M., Koebel, M., Kröcher, O., Schnyder, B., Wokaun, A.: Catalytic oxidation of nitrogen monoxide over Pt/ $\mathrm{SiO}_{2}$. Appl Catal B Environ 50, 73-82 (2003)

9. Olsson, L., Fridell, E.: The influence of Pt oxide formation and $\mathrm{Pt}$ dispersion on the reactions $\mathrm{NO}_{2} \Leftrightarrow \mathrm{NO}+1 / 2 \mathrm{O}_{2}$ over $\mathrm{Pt} / \mathrm{Al}_{2} \mathrm{O}_{3}$ and $\mathrm{Pt} / \mathrm{BaO} / \mathrm{Al}_{2} \mathrm{O}_{3}$. J Catal 210, 340-353 (2002)

10. Bandl-Konrad B., Weibel M., Krutzsch B., Massner A., Gärtner U., Realabgasuntersuchungen und detaillierte experimentelle Untersuchungen zum Einfluss von $\mathrm{CO}$ auf die $\mathrm{NO}_{2}$-Bildung, FAD Konferenz Dresden: presentation (2012)

11. Arvajová, A., Kocí, P., Schmeißer, V., Weibel, M.: The impact of $\mathrm{CO}$ and $\mathrm{C}_{3} \mathrm{H}_{6}$ pulses on $\mathrm{PtO}_{\mathrm{x}}$ reduction and $\mathrm{NO}$ oxidation in a diesel oxidation catalyst. Appl Catal B Environ 181, 644-650 (2016)

12. Voltz, S., Morgan, C., Liederman, D., Jacob, S.: Kinetic study of carbon monoxide and propylene oxidation on platinum catalysts. Ind Eng Chem Prod Res Devolp 12, 294-301 (1973)

13. Russell, A., Henry, C., Currier, N., Yezerets, A., Epling, W. Spatially resolved temperature and gas species concentration changes during $\mathrm{C}_{3} \mathrm{H}_{6}$ oxidation over a $\mathrm{Pt} / \mathrm{Al}_{2} \mathrm{O}_{3}$ catalyst following sulfur exposure. Appl Catal A Gen 397, 272-284 (2011) 